\title{
PRIORITY OF LIBERTY UNDER NON-IDEAL CIRCURMSTANCES
}

\author{
Prioridade da liberdade em circunstâncias não ideais
}

Leandro Martins Zanitelli

UFMG

\begin{abstract}
This work addresses the applicability of Rawls's theory of justice in non-ideal circumstances. The goal, more particularly, is to assess the urgency role that Rawls and some of his interpreters confer to justice of fairness under non-ideal circumstances. In Rawls's case, the urgency role means, in sum, that infringements to the first principle of justice (the basic liberties principle) must be treated as more serious and urging than infringements to the second principle. The paper's main conclusion is that a "strong" understanding of that role has unbearable consequences, worse still than those entailed by the same relation of lexical priority between the two principles under (ideal) conditions of strict compliance. The problem is that, in circumstances of no strict compliance, scarcity of political resources may impose total neglect of the second principle.
\end{abstract}

Keywords: Liberty, Priority, Non-Ideal Theory, Strict Compliance, Rawls.

Resumo: O trabalho trata da aplicação da teoria da justiça de Rawls em circunstâncias não ideais. O objetivo, mais particularmente, é avaliar o papel de urgência que Rawls e alguns de seus comentadores conferem à justiça como equidade em circunstancias não ideais. No caso de Rawls, o papel de urgência significa, em suma, que violações ao primeiro princípio de justiça (o princípio das liberdades básicas) devem ser consideradas mais graves e urgentes que violações ao segundo princípio. A principal conclusão do artigo é que uma interpretação "forte" desse papel tem consequências indesejáveis, piores ainda do que as implicadas pela mesma relação de prioridade léxica entre os dois princípios sob a condição (ideal) de obediência estrita. O problema é que, em circunstâncias de não obediência estrita, a escassez de meios políticos necessários para fazer melhorias institucionais pode impor o abandono total dos temas atinentes ao segundo princípio.

Palavras-chave: Liberdade, Prioridade, Teoria Não Ideal, Obediência Estrita, Rawls.

\section{Introduction}

This work addresses the applicability of Rawls's theory of justice in non-ideal circumstances. The goal, more particularly, is to assess the urgency role that Rawls $(1999,216)$ and some of his interpreters (Stemplowska and Swift 2014, 117) confer to justice of fairness under non-ideal circumstances - i.e. circumstances in which the strict compliance condition is not met. In Rawls's case, the target role means, in sum, that infringements to the first principle of justice (the basic liberties principles) must be treated as more serious and urging than infringements to the second principle, the same holding for the first part of the second principle (the fair equality of opportunity principle) in face of the second one (the difference principle).

The paper's main conclusion is that a "strong" understanding of this urgency role has unbearable consequences, worse still than those entailed by the same relations of lexical priority 
between principles under (ideal) conditions of strict compliance. Regarding, for example, the priority of the first principle over the second one, a strong interpretation of the urgency would imply that violations of basic liberties are always more serious than violations of fair equality of opportunity or the difference principle. As a consequence, it would be always more urging to face impairments of basic liberties than seek for a fairer distribution of opportunities, income and wealth. It follows further that, according to the target role, institutional improvements related to the second principle should be postponed whenever they pose some obstacle to advancements in the basic liberties realm. The problem is that, in circumstances of no strict compliance, scarcity of political means may thus impose a total neglect of the second principle.

The paper is organized as follows. The first section tries to clarify the contrast between ideal and non-ideal theory, drawing on a distinction first suggested by Hamlin and Stemplowska (2012) between ideal theory (IT), non-ideal theory (NIT) and theory of ideals (TI). The section also presents a way of distinguishing between IT and NIT based on the plausibility of a theory's assumptions. The second section directs the focus to Rawls's theory of justice, which is presented as a case of TI followed by a theory about social institutions which is best classified as an IT in face of its strict compliance assumption. The third section introduces a Rawlsian NIT, which is conceived of as a version of Rawls's theory of justice, justice as fairness, in which the strict compliance condition is abandoned. Two roles are allegedly performed by Rawls's $\mathrm{TI}$ and its corresponding IT in non-ideal circumstances, the target and urgency role. The fourth section then moves to the article's core issue, the unpalatable implications of the urgency role constructed in a "strong" way. The fifth and last section enlists some possible solutions to the urgency role problem. One of those solutions consists of IT playing just the target role (thus jettisoning the urgency role); another one is to allow for the two roles to be weighed; a third solution is to construct the urgency role in a "weak" way, while a forth and final one is to moderate basic liberties' demands.

\section{Ideal and non-ideal theories of justice}

The difference between ideal (IT) and non-ideal (NIT) theory may be constructed in several ways (Hamlin and Stemplowska 2012; Valentini 2012). First in this section, I argue for one way to make this distinction. I then proceed by addressing Rawls's theory of justice, focusing on its strict compliance assumption.

As Hamlin and Stemplowska (2012) propose, it is helpful to add to the ideal/non-ideal dichotomy a third concept, that of a "theory of ideals" (TI). A TI is a theory about values or principles (what values there are, how they relate to each other, etc.). IT and NIT, on the other 
hand, are theories about states of affairs. We are interested here in a particular subset of IT and $\mathrm{NIT}$, constituted by theories about social institutions. ${ }^{1}$ Let us take $\mathrm{TI}$ as a theory on values or principles and IT and NIT (or the subset of them we are interested in) as theories about the institutions fitting, under different conditions, the prescriptions of the TI. For example, it is the task of IT and NIT (whichever is the case) to assert which is the fairest design of tax institutions. In order to perform this task, IT (or NIT) must appeal to the principles about just taxation established by a TI.

Consider now the difference between IT and NIT. Remember we are focusing on theories about the moral status of social institutions. Any theory of this sort must rest on some conditions, the conditions under which the theory holds true. Returning to the example, a theory about just taxes may state that consumption tax is fairer than income tax as long as income inequality is below a given threshold. A way to distinguish IT and NIT, thus, is by assessing the plausibility of the conditions a theory assumes. The less plausible these conditions are, the more ideal the theory will be.

Before proceeding, a few remarks on the plausibility standard for distinguishing between IT and NIT. First, as it is easy to note, idealness according to this standard becomes a matter of degree. There is, strictly speaking, neither IT nor NIT, but more or less ideal theories, depending on the lesser or greater plausibility of the conditions assumed. Second, as a theory usually draws on several conditions, comparisons of idealness may be hard to exact, since a same theory may work under a set of conditions with variable plausibility. This would be a problem if the goal of the suggested standard were to render comparisons possible, but not if, as it is the case, its aim is just to clarify the sense in which a theory is referred to as IT or NIT. Third, it should be noticed that the existence of some social institutions may be among the conditions set by a theory. For example, it might be affirmed that educational handicap is the fairest criterion to high-school admission as long as institutional steps for assuring at least a rough equality of opportunity (e.g. inheritance and gift taxes) were taken. Conditions of this sort, or "institutional conditions" are typical of partial institutional theories or theories about the justice of only a subset of social institutions. Theories of justice (both IT and NIT) can be partial in a great variety of ways - for example, by focusing on taxation (while ignoring social spending) or domestic institutions in general (while ignoring global ones). Forth, a condition's plausibility is time and space relative. Let us take, for example, a theory according to which institution $a$ is

\footnotetext{
${ }^{1}$ It is not necessary to enter in details about the concept of institutions as the subject of theories of justice. Rawls, as known, treats certain institutions - those belonging to the "basic structure of society," - as the primary concern of social justice (Rawls 1999, 3).
} 
fairer than $b$ as long as significant immigration is absent. This condition is more plausible to some societies than to others, and more or less plausible at different times. Fifth, plausibility and political feasibility should not be confused. ${ }^{2}$ A $90 \%$ inheritance tax rate may be feasible for the parliament of a given country (in the sense that the parliament is able to impose the tax, if only it wants it) without being plausible (at least in the near future), since it is not likely that the tax will be enacted.

\section{Rawls and the strict compliance assumption}

Let us focus now on Rawls's theory of justice. Rawls's conception of justice (“justice as fairness") is constituted by two principles. The first is the basic liberties principle, which assures to every citizen the equal basic liberties required for the full development and exercise of two fundamental moral capacities, the capacities for a conception of the good and for a sense of justice (Rawls 2001, 42-45). The second principle encompasses fair equality of opportunity (its first subpart) and the difference principle (the second subpart). Fair equality of opportunity is more than just formal equality, since it is also sensible to the effects of social contingencies (like differences in educational access) over opportunities in the course of a person's life (Rawls 1999, 63). The difference principle regulates the distribution of primary goods like income, wealth and the social bases of self-respect. According to this last principle, distribution of such primary goods should be to the greatest advantage of the worst-off citizens (Rawls 1999, 67-69). There are, finally, "lexical" (or unconditioned) priorities between those principles. The first principle is lexically prior to the second one (Rawls 1999, 38), whereas fair equality of opportunity principle is prior to the difference principle (Rawls 1999, 77).

The principles of justice as fairness hold for the basic structure of society, which Rawls defines as "the way in which the major social institutions distribute fundamental rights and duties and determine the division of advantages from social cooperation." Rawls's theory can hence be understood as a $\mathrm{TI}$ (a theory about the principles of justice) followed by a theory about the social institutions that are fitted to attend TI's requirements. $^{3}$

By assuming strict compliance, Rawls's writings about social institutions are often regarded as IT (Simmons 2010, 7-9; Stemplowska and Swift 2014, 113). Justice as fairness is meant to apply to the institutions of a well-ordered society, which is defined as one in which "everyone is presumed to act justly and to do his part in upholding just institutions" (Rawls 1990,

\footnotetext{
${ }^{2}$ On that difference, see Zanitelli (2016).

3 For "property-owning democracy" and "liberal socialism" as institutional schemes prone to comply with the principles of justice as fairness, see Rawls (2001, 137-140).
} 
8). Though Rawls's conception of justice also rests on other important assumptions, ${ }^{4}$ strict compliance will be the focus here.

One could say that Rawls's concept of strict compliance involves not just one, but two kinds of conformity - that we are dealing, strictly speaking, with two conditions rather than one. There is, in the first place, institutional compliance, i.e. compliance of institutions (in Rawls's case, the institutions belonging to the basic structure) with justice. Second, strict compliance also involves individual compliance with social rules. Claims about the justice of a singular aspect of society's basic structure hence hold under two conditions: that the remaining parts of that structure (besides the one under analysis) are in conformity with justice (institutional condition) and that their rules are followed by individual citizens (individual condition). The institutional condition, it should be noted, does not prevent us from making claims about particular institutional issues - for example, about the superior fairness of taxing consumption rather than income. ${ }^{5}$ But the institutional condition of strict compliance renders the true of these particular claims conditional upon the situation of other segments of the institutional order (more precisely, conditional on the conformity of those segments with the principles of justice as fairness). ${ }^{6}$ As to the individual condition, it should be added that what is assumed in this case is not any sort of compliance - like, for example, compliance obtained through coercion - since citizens in Rawls's ideal scenario abide by the rules out of a sense of justice (Rawls 1999, 398).

How ideal is a theory conditioned on strict compliance, so understood? Take first institutional compliance. It is clear that the plausibility of the institutional condition depends on the principles that must be followed. Principles like fair equality of opportunity and the difference principle are comparatively demanding, what makes Rawls's theory rather ideal. With other justice principles, strict institutional compliance may be more easily achieved, thus attenuating the idealness of a theory resting on the strict compliance assumption.

\footnotetext{
${ }^{4}$ For example, that society is a closed system isolated from other societies (Rawls 1999, 7); that favorable circumstances to a democratic regime, including certain material abundance, are in place (Rawls 2001, 47), and that all citizens are able to do productive work (Rawls 2001, 170).

${ }^{5}$ Moreover, the condition at stake is only intelligible when we are making a partial claim. Suppose, contrary to this, that we want to ascertain which complete institutional arrangement is best. In this case, it would not make sense to enact particular conclusions as long as other institutions are in accordance with justice, since our inquiry is about knowing what those institutions are.

${ }^{6}$ It may not be possible, however, to assess which of institutional rules $a$ and $b$ is fairer under the condition of other institutions compliance if we don't know which institutions are those. Comparison between $a$ and $b$, in other words, may depend on the remaining institutions - those to which $a$ or $b$ will be added in a perfect scenario. This is the case in which partial theorizing is pointless.
} 
Something similar applies to the individual condition. In a general way, citizens' strict compliance is rather implausible. ${ }^{7}$ Still, there may be rules more prone to be followed, so that the plausibility of the individual condition also hinges (among other factors) upon the content of justice principles and of the institutional measures required by them. A complication in this respect is that, for Rawls, the truth of a conception of justice is also conditioned upon its principles being not too difficult to abide by. ${ }^{8}$

The fact that the principles of justice as fairness hold under the strict compliance assumption does not entail that the same principles will be jettisoned once this assumption is relaxed. What Rawls calls IT is just a theory developed under (among others) the strict compliance condition, what in itself says nothing about the circumstances where this condition is not met. Furthermore, as we will see in the next section, Rawls believes that his IT has implications for the (non-ideal) circumstances where strict compliance does not hold.

\section{Relaxing the strict compliance assumption: the target and urgency roles}

In the precedent section, we saw that the institutions of a Rawlsian just society must conform to the principles of basic liberties, fair equality of opportunity and the difference principle. We also saw that social institutions must abide by priority rules governing the relations between these principles - the priority of the first principle (the basic liberties principle) over the second one and of fair equality of opportunity over the difference principle. We also discussed strict compliance as one of the features of a well-ordered society in Rawls's terms. A just basic structure, therefore, is one where institutions abide by Rawls's principles under the conditions of institutional and individual compliance.

We have to deal now with the case in which the strict compliance assumption is relaxed. Let us focus here on abandoning the institutional component of this assumption -i.e. in the case in which institutions of a society's basic structure violate the principles of justice as fairness. Since a theory developed for this case (one, thus, that withdraws the institutional condition) is a theory drawing upon conditions that are, ceteris paribus, more plausible, we can refer to that case as NIT. The issue which concerns us is: what are the implications of Rawls's TI (the principles of justice and fairness and the lexical priorities between them) for a NIT, so understood?

\footnotetext{
7 "Even if we understand "strictly" as "almost strictly". In Justice as fairness, Rawls adds the adverb 'nearly' to the definition of strict compliance: "strict compliance means that (nearly) everyone strictly complies with, and so abides by, the principles of justice" (Rawls 2001, 13).

${ }^{8}$ According to Rawls $(1999,153)$, before reaching an agreement on the principles of justice, the parties in the original position take into account the "strains of commitment". They would then reject proposals whose consequences may be too hard to live with.
} 
What Rawls has to say on that matter is puzzling. On one hand, he alerts that the principles of justice as fairness and their priorities are defended for with the strict compliance assumption in mind, so that "under less than favorable conditions," it is possible that "the principles and their lexical order ... no longer hold" (Rawls 1999, 216). On the other hand, Rawls also states that NIT draws on TI. As he explains $(1999,216)$ :

Viewing the theory of justice as a whole, the ideal part presents a conception of a just society that we are to achieve if we can. Existing institutions are to be judged in the light of this conception and held to be unjust to the extent that they depart from it without sufficient reason. The lexical ranking of the principles specifies which elements of the ideal are relatively more urgent, and the priority rules this ordering suggests are to be applied to nonideal cases as well. Thus as far as circumstances permit, we have a natural duty to remove any injustices, beginning with the most grievous as identified by the extent of the deviation from perfect justice. ${ }^{9}$

Stemplowska and Swift $(2014,117)$ construct the above passage as assigning IT two roles in face of NIT. The first is the target role: by describing a given institutional state of affairs as just, IT helps NIT by setting a goal to be pursued. Second, IT (or, more precisely, the TI on which IT rests) provides NIT with an urgency role: IT orients NIT about which injustices should be dealt with first, with the urgency of a given reform change being determined in accordance with the lexical priorities holding between $\mathrm{Tl}^{\prime}$ s principles.

We have two problems here. One is the apparent contradiction between the passage in which Rawls expresses doubt on the validity of the principles of justice as fairness in cases where the strict compliance requirement is not met and the last passage, in which the target and urgency roles are introduced. Another problem is the coexistence of the two roles. Let us begin by the second problem.

Consider, first, the issue of the target role's meaning. One of that role's possible meanings is rather trivial. Since IT presents us with a perfectly just institutional scheme, it is clear that we should aim at such scheme, to the extent, at least, that we are concerned with justice. In order not be reduced to a platitude, the target role must therefore be more than just something we should aim at. A suggestion in that respect is that the target role requires us to act strategically in matters of NIT, in the following sense. Suppose that $a$ and $b$ are both states of affairs with imperfect institutions (so strict compliance does not hold) and that we have reasons to prefer $a$ over $b$. These reasons nonetheless, we may end up having to pick $b$ instead of $a$ if the former is more likely than the latter to lead us to the perfect state. Notice that the case is not about measuring distance from either $a$ or $b$ to perfect justice: we pick $b$ instead of $a$

\footnotetext{
${ }^{9}$ For a similar reasoning, see Rawls $(2001,13)$.
} 
because not because $b$ is closer to perfect justice than $a$, but because $b$ is a more likely path to a perfectly just regime than $a$.

The problem with constructing the target role in this last way is that it renders such role rather unattractive. Suppose we have strong reasons (of justice or others) to prefer $a$ over $b$, that the chances of reaching perfect institutions are overall modest and only slightly bigger in the case of $b$ than in the case of $a$. In that case, it would be odd to pick $b$ instead of $a$ just because $b$ increases (slightly) our chances to arrive at a perfect state. Such an extreme version of the target role is, nonetheless, seemingly endorsed by Simmons (2010). Arguing for an eminently transitional NIT, Simmons states that it is not a condition to support a policy measure $m$ leading to a state of affairs $s$ that $s$ is better than the current state of affairs, since "if it is necessary to take one step backward in order to take two steps forward, Rawlsian nonideal theory will endorse that step 'away from' resemblance to the ideal" (Simmons 2010, 23). This does not mean that "anything goes" in order to achieve a perfect order, since Simmons rejects actions that, although suited to bring us to the target, are morally abject. ${ }^{10}$

As to the urgency role, a first remark is that this one and the target role (constructed in the strategic way above suggested) are potentially conflicting. To see why, assume that there are two sources of injustice, $x$ and $y$, and that $X$ and $Y$ are ways to fight them, respectively. $X$ and $Y$ are both feasible policies, but not conjointly feasible, so we have to choose which of them to undertake first. As injustice coming from $x$ is worse than $y$, the urgency role requires us to do $x$ before $\mathrm{Y}$. It could be, nonetheless, that $\mathrm{Y}$ will render a perfect state of affairs more likely. Thus, according to the target role, we should go ahead with $\mathrm{Y}$, not $\mathrm{X}$.

Stemplowska and Swift solve the problem by granting priority to the urgency role. According to them $(2012,117)$, "the basic idea (...) is that ideal theory both provides the target of reforms undertaken in nonideal circumstances and constrains the route for getting to it by specifying the sequence in which reforms should be undertaken." How much the target role is diminished by this proposal hinges on our ability to compare the urgency of several policy measures. The more often we are able to assert that some sort of injustice is more hideous than

\footnotetext{
${ }^{10}$ Another interpretation of the target role is defended by Sen (2009), according to whom the aim of describing a perfect state of affairs is to allow for comparison between imperfect states. The target role, on this account, consists of determining how unjust is an imperfect state $a$ on the basis of how far is $a$ (as compared with other imperfect situations $b, c . .$.$) from the perfect state. Sen (2009, 15-16) criticizes the$ target role so understood by famously claiming that, in order to compare two imperfect states, IT is neither necessary (indeed, such comparison depends upon a TI, not an IT) nor sufficient (indeed, it is enough to have a TI). Sen further argues that it is hard to measure "distance" between a perfect and an imperfect state, as well as that proximity and desirability are distinct qualities, so that a state $a$ closer to perfection than $b$ may be nonetheless less desirable than $b$.
} 
another one, the greater the pursuit of a perfect state of affairs will be constrained by the need to fix worse instances of injustice first.

Let us focus now on the urgency role. In one of the passages transcribed above, Rawls says that IT is capable of assessing the severity of an injustice and the urgency of taking steps to fighting it. How bad an injustice is it is something to be ascertained according with the lexical order of the principles of justice as fairness, as "the lexical ranking of the principles specifies which elements of the ideal are relatively more urgent" (Rawls 1999, 216). Hence infringements to the basic liberties principle are worse than infringements to fair equality of opportunity, which are worse, in turn, than infringements to the difference principle. This, however, seems to contradict the claim that the principles of justice as fairness and their lexical order are set with the ideal case in mind and, accordingly, that under different (i.e. non-ideal) circumstances, "it is possible that they no longer hold" (Rawls 1999, 216).

The fact that these both passages are contiguous strengths the case for finding a way to reconciliate them. One possible interpretation is that Rawls are not hesitating about the principles and their priorities is any circumstances of non-strict compliance, but only in those in which some minimal conditions are lacking. Rawls distinguishes, as it is known, a special conception of justice - including the principles and their lexical order - from a general conception under which this order does not hold (Rawls 1999, 54-55). The general conception applies to circumstances where material scarcity is extreme, as well as to those where the cultural background needed to run a constitutional democracy is absent. Very poor societies ${ }^{11}$ or those lacking the cultural requisites for democratic institutions are not subjected, therefore, to the priority rules of the special conception.

One inconvenient of that interpretation is that Rawls is clear on the difference between the general and special conceptions of justice, while the passage under comment only expresses a doubt ("it is possible that they no longer hold," emphasis mine) about the priority rules being applied to the cases Rawls has in mind. Another inconvenient is that, in the same paragraph in which this doubt is expressed, Rawls refers to the strict compliance assumption and IT's ability to guide us in circumstances of injustice, and injustice is not limited, of course, to the circumstances where the conditions of moderate abundance and democratic culture are lacking.

Let us then assume that Rawls's TI (the principles of justice as fairness and their lexical order) holds for circumstances in which, while compliance is not strict, the two conditions of the special conception are met. Let us assume also that such $\mathrm{Tl}$ (first developed under the strict

\footnotetext{
${ }^{11}$ Hence it is not the case that priority of liberty is conditioned to high levels of income and wealth (Rawls 2001, 47, n. 12).
} 
compliance assumption) plays the urgency role in the sense stated before, so that the seriousness of an injustice and the urgency to eliminate it, both to be ascertained by NIT, are determined according to the principles and priority rules of the TI. In the following section, we shall discuss some of the implications of those assumptions.

\section{Urgency role and priority of liberty}

Let us consider now some implications of the urgency role. Before proceeding, however, it is useful to state some points we will be drawing on: a) the urgency role is prior to the target role; b) urgency is ascertained with the lexical order of Tl's principles in mind, except when the requisites of material abundance and democratic culture are not met (as to the priority rules between principles, the analysis below shall be restrained to the priority of the first principle over the second one). ${ }^{12}$

Consider now a "strong" interpretation of item $b$ supra. This interpretation goes as follows: (1) "It is always worse to violate the first principle, so that eliminating violations against the first principle is always more urgent than eliminating violations against the second principle."

What are the implications of this claim about the superior urgency of eradicating violations to basic liberties? If we can end injustices $a$ and $b$, but cannot end both at the same time - that is, if the political resources we have to fight injustices are not enough to eliminate $a$ and $b$ simultaneously - then the greater urgency of $a$ entails that, all else being the same, we ought to get ride of $a$ first. (1) entails, thus, the following:

(2) "Unless we have the political means to do both at the same time, measures to satisfy the second principle must be postponed until the first principle is fully met."

(3) "If needed to satisfy the first principle, we ought to take steps that will lead us to a worse situation in the light of the second principle."

(3) may seem particularly odd, yet it is nothing but a special case of the maxim according to which we ought to prefer a lesser injustice over a greater one. It is implied, in any event, by (1): if we have to choose between preserving the status quo and moving to a state of affairs where a violation of the first principle is abolished, the urgency role requires us to do the latter, even if the new state fares worse, from a second principle perspective, than the current one.

\footnotetext{
${ }^{12}$ We will focus on the priority of liberty here, since this seems more important to Rawls than the priority of the first part of the second principle (fair equality of opportunity) over the second one (the difference principle), about which Rawls expresses doubt in a late writing (Rawls 2001, 163, n. 44).
} 
Sticking with the status quo in this case would be tantamount to missing an opportunity to end a more urgent injustice so as to avoid a less urgent one.

Constructed in this strong way, the urgency role has serious consequences for Rawlsian politics under non-ideal circumstances (i.e. circumstances in which compliance is not strict). Assuming our lack of political means to realize all the principles of justice as fairness at once, no policy favoring fair equality of opportunity (like investing in public schools and health care) would be allowed while first principle's demands were not fully exhausted. Furthermore, even policies contrary to equality of opportunity would have to be endorsed if needed for liberties' sake. Something similar would hold for measures affecting the interests of the worst-off citizens, the citizens whose advantage must be maximized according to the difference principle.

Criticisms of that kind may sound familiar, ${ }^{13}$ but the remarks made above are peculiar in the following sense. No matter how odd priority rules may seem under the assumption of strict compliance, the case is still worse when that assumption is given away. The Rawlsian ideal case (where strict compliance holds) is privileged, since there we don't need any further political means to arrive to a perfect point in which basic liberties are guaranteed. Surely, one still needs resources in order to keep such perfect state going on, but such resources, it is fair to assume, are considerably more modest than those needed to reach a situation of full compliance in the first place, for two reasons. First, it is overall easier to maintain a state of compliance than getting to one. Even if, in order to preserve compliance, one must incur in some institutional changes from time to time, the tendency is to these changes be comparatively small. Second, the ideal case, on Rawls's account, involves citizens' willingness to support just institutions. While this does not necessarily render the task of preserving basic liberties simple, it surely helps to achieve it.

Whenever the strict compliance condition is lacking, the volume of political resources to employ in order to suit justice demands becomes greater. If the current shape of our institutions is unsatisfactory, we will need to change them. For this, we will not always count on other citizens' willingness to support just reforms and to cooperate to their implementation. The more resources are needed to some institutional improvement, the greater the opportunity costs of employing those resources to do a particular reform instead of other. It is not hard to imagine an ideal Rawlsian world in which political leaders are not forced to choose between protecting

\footnotetext{
${ }^{13}$ For examples of criticisms against the priority of liberty, se Barry (1973) and Hart (1973). For examples of criticisms against the priority of fair equality of opportunity over the difference principle, see Alexander (1986) and Arneson (1999). Pogge (1995) discusses some problems faced by the basic liberties principles in circumstances of less than full compliance, but his focus is, unlike mine, on cases of individual (instead of institutional) non-compliance.
} 
liberties and assuring fair equality of opportunity, for example. In the real world, however, political effort needed to perform one of those tasks will often, if not always, prevent performing the other.

\section{Possible solutions}

It is one thing to accept that, in a society whose institutions already comply with justice and whose citizens support these institutions and abide by the rules imposed by them, fair equality of opportunity and a distribution of wealth favoring the worst-off citizens should be sacrificed, to some extent, for the sake of basic liberties. Another, rather different one is to accept that, in a society in which such ideal state is absent, the political means to make institutional improvements be exhausted for basic liberties purposes, as it would be the case if the urgency role of Rawls's TI is understood in the strong way described above. Let us consider some possible solutions to this conundrum:

\section{1) Assigning to the $\mathrm{TI}$ and its corresponding IT only the target role}

If $\mathrm{TI}$ and its corresponding IT played only the target role, the problem of resources for change being depleted by basic liberties would likely disappear. NIT, in this setting, would deal with reforms suited to reach the perfect institutional state of IT. The best strategy to get to this state might consist of first satisfying the basic liberties principle fully (case in which, by coincidence, the urgency role would also be performed). But achieving the perfect institutional state might also involve the gradual fulfillment of the two principles simultaneously. In the absence of any commitment to the urgency role, lexical order between principles would be disregarded in this case. Such order would thus be a feature of Rawls's TI holding only for IT.

2) Cancelling the priority of the urgency role over the target role

Another solution is to withdraw the priority of the urgency role over the target role. In this case, the fact that a reform $a$ is more urgent than another $b$ would provide only a pro tanto reason to prefer the former, since target concerns may end up favoring $b$, all things considered. Once such weighing between the two roles is allowed, priority rules are softened. Even if $a$ is more urgent than $b$ (for example, because $a$ rectifies a liberty deficit, while $b$ raises worst-off citizens' position), the greater probability of $b$ leading to a perfect state of affairs may be enough to make the case of proceeding with $b$ instead of $a$.

3) Constructing the urgency role in a weaker way 
Like the precedent one, this solution moderates the consequences of constructing the urgency role in the (strong) way suggested above. The difference is that, in the present case, softening of priority rules in NIT comes from a reformulation of the urgency standard (rather than from weighing it with target considerations). A weaker interpretation allows for instances where changing institutions to improve matters in the second principle realm would be more urgent than meeting basic liberties requirements.

4) Constructing the basic liberties principle in a weaker way

Constructing the basic liberties principle so as to render it easier to satisfy is another way out. To the extent that complying with first principle requirements do not consume substantial political resources (a consequence of interpreting that principle in a less demanding fashion), it will be more often the case that complying with basic liberties in non-ideal circumstances will not prevent taking steps for realizing fair equality of opportunity and the difference principle.

There is a tension, however, between this last proposal and the account of basic liberties that emerges from Rawls's writings. It is true that, in one of the most known reformulations of his theory of justice, Rawls $(1993,332)$ rejected a maximizing version of the first principle in favor of one following which equal basic liberties are prioritized only to the extent needed to "the adequate development and the full and informed exercise" of the two moral capacities, the capacities for a conception of the good and for a sense of justice. As a consequence, the first principle does not include all specifications of basic liberties, but only those more intimately related to the development and exercise of the mentioned capacities. Yet basic liberties are presented as a "framework of legally protected paths and opportunities" (Rawls 1993, 325). Thus even circumscribed to the essential cases mentioned above, legal protection of rights and liberties such as life, integrity, free speech, liberty of conscience and rule-of-law requires a rather robust institutional apparatus, one whose design and maintenance demand a non-negligible effort by authorities and citizens in general. ${ }^{14}$ To this one must add the fact that fair value of political liberties is included in the first principle, which requires, as a consequence, that chances of being elected for public offices and of influencing political decisions must not be (at least to some extent) affected by the distribution of wealth (Rawls 1993, 327). Fair value of political liberties requires institutions able to prevent political life from being controlled by wealthy

\footnotetext{
${ }^{14}$ As Pogge (1995) points out, the basic liberties principle is "not about legal rights as such, but about their objects: about whether they will actually enjoy the freedoms in question. Legal enumeration is a means to this end ... but certainly not a sufficient one".
} 
people, owners of productive means (in capitalist regimes) and bureaucrats (in socialist regimes) (Rawls 1993, p. 328). This would be an enormous challenge, likely to absorb at least a significant part of the resources available for institutional reform.

\section{References}

Alexander, Larry, 1986, Fair Equality of Opportunity: John Rawls' (best) Forgotten Principle, Philosophy Research Articles 11: 197-208.

Arneson, Richard, 1999, Against Rawlsian Equality of Opportunity, Philosophical Studies 93: 77112.

Barry, Brian, 1973, Rawls and the Priority of Liberty, Philosophy \& Public Affairs 2: 274-90.

Hamlin, Alan, and Stemplowska, Zofia, 2012, Theory, Ideal Theory and the Theory of Ideals, Political Studies 10: 48-62.

Hart, Herbert L. A., 1973, Rawls on Liberty and its Priority, University of Chicago Law Review 40 : 534-55.

Pogge, Thomas W., 1995, Three Problems with Contractarian-Consequentialist Ways of Assessing Social Institutions, Social Philosophy and Policy 12: 241-66.

Rawls, John, 1993, Political Liberalism, New York: Columbia University Press

Rawls, John, 1999, A Theory of Justice, Cambridge: Belknap Press.

Rawls, John, 2001, Justice as Fairness: A Restatement, Cambridge: Belknap Press.

Sen, Amartya, 2009, The Idea of Justice, Cambridge: Belknap Press.

Simmons, A. John, 2010, Ideal and Non-Ideal Theory, Philosophy \& Public Affairs 38: 5-36.

Stemplowska, Zofia, and Swift, Adam, 2014, Rawls on Ideal and Nonideal Theory, in Mandle, Jon, and Reidy, David A., A Companion to Rawls, Malden: Blackwell.

Valentini, Laura, 2012, Ideal Vs. Non-ideal Theory: A Conceptual Map, Philosophy Compass 7: 654-64.

Zanitelli, Leandro Martins, 2016, Institutional Perfection or Improvement of Imperfect Institutions? An Essay on the Methodological Status of Perfect But Unfeasible Institutional Regimes, Revista Latinoamericana de Filosofía Política 5: 1-30. 